\title{
O ENSINO DO ALUNO COM DEFICIÊNCIA NA ESCOLA REGULAR
}

\author{
Natália Costa de FELICIO ${ }^{1}$ \\ Cristina Cinto Araújo PEDROSO ${ }^{2}$
}

RESUMO: Este estudo objetivou analisar a organização do ensino para os alunos com deficiências, em classes comuns do Ensino Fundamental I de uma escola pública estadual, no interior paulista. Objetivou-se especificamente: a) analisar as concepções dos professores sobre educação inclusiva e ensino de alunos com deficiência; b) analisar as aulas desenvolvidas na classe comum e na instituição especializada e c) analisar como tem ocorrido a parceria entre escola comum e instituição especializada na organização do ensino para o aluno com deficiência. Os dados foram obtidos por meio da entrevista semi-estruturada com os professores da escola comum e da instituição especializada e da observação participante das aulas nos dois contextos de ensino nas turmas com alunos deficientes visuais inseridos. Os resultados evidenciaram que as seis professoras entrevistadas não apresentam formação específica para o ensino de alunos com deficiência. Consequentemente, as quatro professores da escola comum não conhecem o conceito de adaptação curricular. A instituição especializada oferece apoio aos professores, entretanto, o mesmo não é continuo e permanente, portanto, não favorece uma cultura de reflexão conjunta do processo ensino-aprendizagem. A observação das aulas na escola regular permitiu verificar que as quatro professoras não planejam em função das especificidades dos alunos com deficiência. Na instituição especializada observou-se que o trabalho pouco se articula ao currículo escolar. Conclui-se, portanto, que a inclusão na escola pública tem avançado apenas em relação ao acesso, mas não em relação à qualidade dos processos escolares.

PALAVRAS-CHAVE: Educação inclusiva. Ensino de alunos com deficiência visual. Formação de professores para educação inclusiva.

\section{Introdução}

Este texto apresenta os resultados de uma pesquisa que teve como objetivo geral analisar a organização do ensino para os alunos com deficiências, em classes comuns do Ensino Fundamental I de uma escola pública estadual, no interior paulista. Tal objetivo geral está pautado por objetivos específicos, a saber: a) analisar as concepções dos professores sobre educação inclusiva e ensino de alunos com deficiência; b) analisar as aulas desenvolvidas na classe comum e na instituição especializada e c) analisar como

\footnotetext{
${ }^{1}$ Graduanda em Pedagogia. USP - Universidade de São Paulo. Faculdade de Filosofia, Ciências e Letras Departamento de Educação, Informação e Comunicação. Ribeirão Preto - SP - Brasil. 14040-901 natifelicio@msn.com.

2 Docente. USP - Universidade de São Paulo. Faculdade de Filosofia, Ciências e Letras - Departamento de Educação, Informação e Comunicação. Ribeirão Preto - SP - Brasil. 14040-901. Membro do Gepefe (Grupo de Estudo e Pesquisa sobre a Formação do Educador - FE/USP) - cpedroso@ ffclrp.usp.br.
} 
tem ocorrido a parceria entre escola comum e instituição especializada na organização do ensino para o aluno com deficiência. O estudo foi realizado no âmbito da iniciação científica, no curso de Pedagogia da Faculdade de Filosofia, Ciências e Letras de Ribeirão Preto.

O estudo relatado se justifica no atual cenário da educação brasileira o qual vem se modificando intensamente nas últimas décadas notadamente como resultado dos movimentos de democratização do acesso à escolarização básica e de educação inclusiva. Justifica-se também na importância de estudos que se proponham a adentrar a sala de aula e analisá-la à luz dos pressupostos da educação inclusiva. Por fim se justifica na relevância de ouvir os professores para que eles possam relatar as suas percepções acerca do ensino de alunos com deficiência tanto na escola comum como na instituição especializada.

A educação inclusiva é entendida como

[...] a garantia, a todos, do acesso contínuo ao espaço comum da vida em sociedade, sociedade essa que deve estar orientada por relações de acolhimento à diversidade humana, de aceitação das diferenças individuais, de esforço coletivo na equiparação de oportunidades de desenvolvimento, com qualidade, em todas as dimensões da vida (BRASIL, 2001a, p. 39-40).

Complementarmente para Rodrigues (2006) a educação inclusiva

não é uma cosmética da educação tradicional e nem uma simples estratégia de melhoria da escola: constitui a promoção da formulação da educação em novas bases que rejeitem a exclusão e promovam uma educação diversa e de qualidade para todos os alunos (RODRIGUES, 2006, p.13).

Como decorrência das políticas de educação inclusiva tem crescido, significativamente, o número de matrícula de alunos com deficiência nas escolas comuns. Essa ampliação pode ser verificada nos indicadores do censo escolar de 2012 (BRASIL, 2013). De acordo com esses dados, é possível verificar que houve um aumento de 9,1\% no número de matrículas de alunos com deficiência, na educação básica. Em 2011, o número de matrículas foi de 752.305; já em 2012, esse contingente passou a ser de 820.433. Além disso, entre os anos de 2007 a 2012 os dados obtidos mostraram avanços referentes à matrícula desse alunado, principalmente na rede pública.

O acesso dos alunos com deficiência aos contextos comuns de ensino tem sido acompanhado, no entanto, de inúmeras dificuldades: professores despreparados e sem 
formação para o ensino desses alunos, falta de recursos específicos, falta de materiais apropriados, dentre outras (MENDES, 2006). Tais limitações têm dificultado que a educação inclusiva promova os avanços esperados em relação ao direito dos alunos com deficiência de usufruírem plenamente a escola, o que significa ter acesso, mas principalmente, nela permanecer e nela aprender.

Considerando a expansão de matrículas, em sua maioria na rede pública de ensino, Pietro (2006, p.35) coloca um desafio a ser enfrentado, o qual seria "não permitir que o direito de educação para todos seja traduzido meramente como cumprimento da obrigação de matricular e manter os alunos com necessidades especiais em classes comuns". Para a mesma autora o objetivo da inclusão escolar é tornar reconhecida e valorizada a diversidade como condição humana favorecedora de aprendizagem. Desse modo, ao invés de "aproximar" o aluno com necessidades educacionais especiais dos chamados padrões de normalidade, a ênfase está na identificação de suas potencialidades, culminando com a construção de alternativas pedagógicas capazes de propiciar condições favoráveis à sua autonomia escolar e social, o que implica uma ampla reorganização das escolas.

Nesse sentido a Resolução CNE/CEB n ${ }^{\circ}$ 2, de 11 de setembro de 2001, que institui as Diretrizes Nacionais para a Educação Especial na Educação Básica, determina que

os sistemas de ensino devem matricular todos os alunos, cabendo às escolas organizar-se para o atendimento aos educandos com necessidades educacionais especiais, assegurando as condições necessárias para uma educação de qualidade para todos (BRASIL, 2001b, p.1).

Nessa mesma direção, a Política Nacional de Educação Especial na perspectiva da Educação Inclusiva (BRASIL, 2008) objetiva

Assegurar a inclusão escolar de alunos com deficiência, transtornos globais do desenvolvimento e altas habilidades/superdotação, orientando os sistemas de ensino para garantir: acesso ao ensino regular, com participação, aprendizagem, e continuidade nos níveis mais elevados do ensino; transversalidade da modalidade de educação especial desde a educação infantil até a educação superior; oferta do atendimento educacional especializado; formação de professores para $o$ atendimento educacional especializado e demais profissionais da educação para a inclusão; participação da família e da comunidade; acessibilidade arquitetônica, nos transportes, nos mobiliários, nas 
comunicação e informação; e articulação intersetorial na implementação das políticas públicas (BRASIL, 2008, p.14).

Pelo exposto acima fica evidente que a educação inclusiva demanda mudanças significativas na organização das escolas, na elaboração dos currículos, na formação dos professores, no estabelecimento das parcerias com os profissionais da educação especial, dentre outros aspectos. Portanto, nesse momento é fundamental analisar as condições que têm sido organizadas para esses alunos na escola pública e como tem sido estabelecida a parceria com instituições especializadas.

\section{Descrição do trabalho desenvolvido}

Esta pesquisa caracteriza-se como um estudo de natureza qualitativa, utilizando as técnicas da observação participante e da entrevista. A observação participante implica a atividade de um pesquisador que observa pessoalmente e de maneira prolongada situações e comportamentos pelos quais se interessa, sendo considerada por Jaccoud e Mayer (2008) uma importante técnica de coleta na área das ciências sociais. A entrevista semiestruturada, por sua vez, é um dos principais caminhos para se realizar a coleta de dados no âmbito da pesquisa qualitativa (TRIVIÑOS, 2006). A entrevista semiestruturada, ao mesmo tempo em que "valoriza a presença do investigador, oferece todas as perspectivas possíveis para que o informante alcance a liberdade e a espontaneidade necessárias, enriquecendo a investigação" (TRIVIÑOS, 2006, p.146). Além disso, a entrevista é o meio mais adequado para se obter determinado tipo de informação, como, por exemplo, a concepção de um sujeito ou de um grupo sobre um determinado objeto (DIAS; OMOTE, 1995).

A pesquisa foi desenvolvida em uma Escola Estadual de Ensino Fundamental (Ciclo I) e em uma instituição especializada no atendimento de alunos com deficiência visual, ambas localizadas em uma cidade de porte médio do interior paulista.

Participaram do estudo quatro professoras da rede regular de ensino e duas professoras de uma instituição especializada no atendimento de deficientes visuais ${ }^{3}$.

\footnotetext{
${ }^{3}$ O termo deficiência visual inclui dois grupos de condições distintas: a cegueira e a baixa visão, as quais se caracterizam por ser a perda total ou parcial respectivamente, congênita ou adquirida. De acordo com BRASIL (2005), a cegueira constitui-se por ser a ausência total da visão, incluindo a perda da capacidade de indicar a projeção de luz. A baixa visão se caracteriza por uma perda severa da visão, não corrigível por meio de tratamento clínico, cirúrgico, nem com uso de óculos convencionais.
} 


\section{Resultados}

Os dados foram discutidos a partir de dois aspectos: as entrevistas e as observações das aulas.

As entrevistas realizadas com as seis professoras permitiram inicialmente conhecer o perfil das mesmas, tal como mostra a Tabela 1. As professoras identificadas pelas siglas P1, P2, P3 e P4 atuam na escola comum e as outras identificadas por P5 e P6 atuam na instituição especializada. As entrevistas foram gravadas e transcritas.

Tabela 1- Mostra o tempo de atuação na área e a formação das professoras entrevistadas

\begin{tabular}{|c|c|c|c|c|}
\hline Professoras & $\begin{array}{c}\text { Tempo de } \\
\text { atuação na } \\
\text { área }\end{array}$ & $\begin{array}{c}\text { Formação em } \\
\text { nível médio } \\
\text { magistério }\end{array}$ & Graduação & $\begin{array}{c}\text { Pós-graduação na } \\
\text { área da Educação }\end{array}$ \\
\hline P1 & 23 anos & Sim & Pedagogia & $\begin{array}{c}\text { Sim (Curso de } \\
\text { Especialização Lato } \\
\text { Sensu em } \\
\text { Psicopedagogia) }\end{array}$ \\
\hline P2 & 23 anos & Sim & Pedagogia & Não \\
\hline P3 & 28 anos & Sim & Pedagogia & Não \\
\hline P4 & 37 anos & Sim & Pedagogia & Não \\
\hline P5 & 1 ano & Não & Matemática & Não \\
\hline P6 & 2 anos & Não & Letras & Não \\
\hline
\end{tabular}

Fonte: elaboração própria.

Em relação à formação os dados mostram que todas as quatro professoras que atuam na escola comum apresentam mais de 20 anos no exercício da docência, em média 28 anos. Contudo, para três delas a experiência em questão foi o primeiro contato com alunos com deficiência na sua sala de aula. Apenas uma vem tendo experiência com alunos com deficiência desde sua formação inicial (Magistério), e mais especificamente com alunos com deficiência visual desde 2003. As duas professoras da instituição especializada apresentam uma experiência muito recente nesse contexto.

Outro aspecto levantado na entrevista remete à questão se na formação inicial elas cursaram disciplinas que contemplassem conteúdos referentes ao ensino de alunos com deficiência. Apenas duas professoras (P1 e P3) ao longo de sua formação cursaram 
disciplinas que abarcavam conteúdos dessa temática. Uma delas citou o curso de pósgraduação e a outra o curso de Magistério (em nível de $2^{\circ}$ grau), entretanto para elas essa formação não fora suficiente para que elas se sentissem capazes de ensinar tais alunos. As outras duas professoras (P2 e P4) não cursaram disciplinas ao longo de sua formação, a P4 fez alusão ao serviço especializado, como fonte de informação e alternativa de formação e apoio para seu trabalho em sala de aula. Entretanto, a Tabela 1 mostra que as professoras P5 e P6 que atuam na instituição especializada também não possuem formação específica para o ensino de alunos com deficiência e não são formadas em Pedagogia, licenciatura com maior proximidade com a área da Educação Especial. Frente a essa realidade cabe indagar: quais as condições reais que a instituição especializada tem de se constituir como espaço de formação continuada para os professores do ensino comum e como espaço de apoio aos alunos com deficiência?

Em relação ao ensino de alunos com deficiência a formação do professor é imprescindível, pois, se o professor não o é único responsável pela organização da escola inclusiva, é a "chave definitiva e importante para a mudança e a melhoria da escola" (PIMENTA, 2002, p. 11). Assim considerado, é preciso que os cursos de licenciatura promovam a reflexão e a produção de conhecimentos sobre essas questões, tal como indica Parecer 9/2001 CNE/CP (BRASIL, 2001c), a Resolução CNE/CP nº. 1/02 (BRASIL, 2002) e o estudo de Pedroso, Campos e Duarte (2013).

A entrevista com as professoras da classe comum evidenciou que todas são favoráveis à inclusão de alunos com deficiência na classe comum, entretanto, nenhuma se sente preparada para ensiná-los. Nas respostas das quatro foram apontados os seguintes aspectos como importantes de serem cuidados: necessidade de formação específica para a inclusão, disponibilização de recursos e materiais e presença na escola de um professor especialista para apoiar o professor da classe comum. Adicionalmente, a entrevista mostrou também que as mesmas têm uma ideia muito vaga e superficial do conceito de adaptação curricular, portanto, conhecimento insuficiente para subsidiar a utilização desse recurso para viabilizar o acesso desses alunos ao currículo escolar.

O conceito de adaptação curricular é muito mais complexo do que foi relatado pelas professoras. Segundo Heredero (2010), as adaptações curriculares são:

Toda e qualquer ação pedagógica que tenha a intenção de flexibilizar o currículo para oferecer respostas educativas às necessidades especiais dos alunos, no contexto escolar. As adaptações são concebidas, então, como instrumento que pode e deve tratar de avançar no desenvolvimento geral de cada pessoa. São, em 
consequência, o conjunto de modificações que se realizam nos objetivos, conteúdos, critérios e procedimentos de avaliação, atividades e metodologia para atender às diferenças individuais dos alunos. Além disso, as adaptações não se centralizarão somente no aluno/a; serão relativas e flexíveis, formarão um contínuo de menor a maior significação, e deverão ser revisadas e avaliadas constantemente (HEREDERO, 2010, p.199-200).

Pelo exposto a implementação de adaptações curriculares requer conhecimento aprofundado sobre as especificidades dos alunos e sobre os recursos específicos que podem auxiliar no acesso ao currículo, o que aponta mais uma vez para a formação dos professores.

$\mathrm{Na}$ entrevista indagou-se também se as professoras recebem orientações sobre o aluno com deficiência visual na escola em que trabalham, constituindo-se em um mecanismo de formação continuada. Pelos relatos todas receberam na escola regular alguma orientação nas reuniões de ATPC. Entretanto, acrescentaram que tais orientações são superficiais, aligeiradas, generalistas, na perspectiva de palestra, sem aprofundar na análise dos casos reais vivenciados pelos professores nas suas turmas de alunos.

As quatro professoras entrevistadas relataram receber apoio da instituição especializada que atende os alunos com deficiência visual. O apoio, entretanto, não é continuo e permanente e depende muito da disponibilidade do professor de procurar a instituição especializada. Dessa maneira, o apoio da instituição especializada ao aluno no contraturno não se articula ao trabalho da escola, portanto, não favorece uma cultura de reflexão conjunta do processo ensino-aprendizagem, ele permanece paralelo com pouca ou nenhuma articulação com o currículo escolar.

A entrevista com as professoras da instituição especializada mostrou que as mesmas acreditam que o trabalho desenvolvido com o aluno com deficiência tem como objetivo reforçar os conteúdos ministrados na sala regular. Entretanto, elas também apontaram a falta de uma parceria mais efetiva e permanente entre os dois seguimentos. Uma delas mencionou que se comunica com a professora da escola regular pelo caderno de bilhetes do aluno. Cabe considerar que esse procedimento não é suficiente para garantir uma reflexão conjunta das práticas pedagógicas e do aproveitamento do aluno.

Para analisar a organização das aulas o pesquisador realizou 8 horas de observação em cada uma das quatro turmas da escola estadual de ensino fundamental com deficientes visuais inseridos. Dessas quatro turmas duas eram de $4^{\circ}$ ano, uma de $5^{\circ}$ 
ano e uma de $2^{\circ}$ ano, totalizando 32 horas de observação nesse contexto. Além disso, observou-se também mais 32 horas na instituição especializada no atendimento oferecido aos mesmos no contraturno da escola. No total foram realizadas, portanto, 64 horas de observação. Tais observações ocorreram durante o segundo semestre de 2012 e foram registradas em diário de campo.

A Tabela 2, a seguir, mostra as características dos quatro alunos participantes das turmas observadas.

Tabela 2 - Idade, gênero, nível de ensino e tipo de deficiência dos alunos deficientes visuais participantes das turmas observadas

\begin{tabular}{|c|c|l|c|c|}
\hline Aluno & Idade & Gênero & Nível de ensino & Tipo de deficiência \\
\hline A1 & 10 & Menino & $4^{\text {o } a n o ~(p e r i ́ o d o ~ d a ~ m a n h a ̃) ~}$ & Baixa visão \\
\hline A2 & 10 & Menino & $4^{\text {o } a n o ~(p e r i ́ o d o ~ d a ~ t a r d e) ~}$ & Cegueira \\
\hline A3 & 9 & Menino & $5^{\text {o } a n o}$ & Baixa visão \\
\hline A4 & 7 & Menina & $2^{\text {o } a n o}$ & Baixa visão \\
\hline
\end{tabular}

Fonte: elaboração própria.

Das quatro turmas observadas verificou-se um aspecto que chamou atenção diz respeito ao planejamento das aulas. Verificou-se que as aulas não são organizadas tendo em vista a especificidades dos alunos com deficiência visual (cegueira e ou baixa visão), pois não se verificou indícios de adaptações curriculares significativas e tampouco o uso de recursos e materiais diferenciados. Foi observado apenas o uso de alguns materiais em Braille ou em letras ampliadas.

As aulas observadas na escola comum parecem que não são submetidas à reflexão das professoras, possivelmente porque elas não contam os conhecimentos necessários para adequar a prática docente às características e necessidades dos alunos com deficiência visual. Os professores parecem agir como se não existissem alunos com deficiência visual nas suas turmas. Sobre essa questão cabe considerar que de acordo com Farias (2009)

[...] o planejamento é uma ação reflexiva, viva e contínua. Uma atividade constante, permeada por um processo de avaliação e revisão sobre o que somos, fazemos e precisamos realizar para atingir nossos objetivos. É um ato decisório, portanto, político, pois nos exige escolhas, opções metodológicas e teóricas. Também é ético, uma vez 
que põe em questão ideias, valores, crenças e projetos que alimentam nossas práticas (FARIAS, 2009, p.107).

Merece destaque as aulas de Língua Portuguesa na turma na qual estava inserido o aluno cego. A professora trabalhava predominantemente com o contar de histórias e a produção de textos. O aluno nessa situação conseguia participar produzindo seus textos com a máquina Braille. No entanto, para corrigi-los a professora precisava do apoio da instituição especializada que fazia a transcrição. $\mathrm{O}$ aluno não contava com o material Ler e Escrever, utilizado pela professora, em Braille. Nas aulas de Matemática a professora apoiava-se no livro didático e no material Ler e Escrever, entretanto, o aluno cego também não contava com os mesmos em Braille, o que restringia a possibilidade de participação e de acessar o mesmo conteúdo trabalhado com os colegas. Além disso, observou-se que a professora utilizava com muita frequência a lousa para passar exercícios para a classe, nesse caso o aluno ficava sem fazer nada e às vezes contava com o apoio de um colega que ditava os exercícios para ele, criando uma situação constrangedora. Não é possível aceitar que a responsabilidade pela organização das condições de ensino, que deveria ocorrer no âmbito oficial, possa ser localizada em um colega. Mesmo que a ajudar seja uma ação formativa ela não pode substituir o compromisso do governo com a questão. Esse dado mostra que a participação do aluno com deficiência visual depende da organização das condições e da disponibilização dos recursos.

Nas turmas dos alunos com baixa visão observou-se que os mesmos contavam com o material Ler e Escrever ampliado, mas apenas de Língua Portuguesa e Matemática. Além disso, apenas as letras são ampliadas, mas não as ilustrações. Da mesma maneira que na turma do aluno cego as professoras também utilizam a lousa e contam com a ajuda de colegas da classe para ditar para os alunos com baixa visão que não enxergavam na lousa.

As observações realizadas na instituição especializada mostraram que o trabalho objetiva primeiramente apoiar o aluno na realização das atividades propostas pela escola regular. Entretanto, verificou-se que esse trabalho se restringe basicamente à realização das tarefas e trabalhos. Assim que isso é concluído os alunos são convidados a realizar outras atividades, portanto, não há oportunidade para aprofundamento e ampliação do currículo escolar. Interessante destacar que a instituição conta com muitos materiais específicos e adaptados para a deficiência visual. Observou-se que não há uma rotina 
constituída de reflexão conjunta das práticas pedagógicas entre os professores da escola comum e da instituição especializada.

\section{Considerações finais}

A realização deste estudo permitiu adentrar a sala de aula na escola comum e analisar a organização do ensino para alunos com deficiência visual inseridos no Ensino Fundamental I. Além disso, foi possível entrevistar os professores e conhecer a percepção deles sobre a educação inclusiva e o ensino desses alunos. Verificou-se que a escola pública estadual está garantindo o direito desses alunos em relação ao acesso, mas não em relação à qualidade dos processos escolares, pois a formação dos professores é insuficiente, não há recursos e materiais específicos disponíveis, não há formação continuada permanente sobre a temática e não há uma cultura de reflexão conjunta com os profissionais da educação especial.

A aproximação com a instituição especializada permitiu verificar que a o trabalho que a mesma desenvolve se articula pouco com o currículo escolar. Portanto, não foi possível identificar um trabalho colaborativo a partir de uma parceria efetiva entre a instituição especializada e a escola regular.

\section{THE TEACHING OF THE STUDENT WITH DISABILITY AT THE REGULAR SCHOOL}

ABSTRACT: This study aimed at analyzing the organization of Education for disabled schoolchildren in regular elementary classes and it was conducted at a public state school in the state of São Paulo, Brazil. The objectives focused on: a) analyzing the teachers' concepts on Inclusive Education and on the teaching of children with disabilities; b) analyzing the classes/lessons given in regular classrooms and in specialized institution; c) analyzing the partnership between regular school and specialized institution in the organization of Education for students with disabilities. Data were collected by means of semi-structured interviews with teachers at regular schools and specialized institution as well as participant observation methods in both contexts with visually impaired students. The results showed that the six teachers interviewed do not have specific training for teaching students with disabilities. Consequently, the four regular school teachers do not have knowledge on the concept of curriculum adaptation. Specialized institution offers technical, pedagogical support to teachers. However, as it is not continuous and permanent, it does not foster the culture of getting together and reflecting upon the teaching-learning process. The observation of classes at regular schools has shown that the four teachers do not plan their classes according to the specificities of students with visual impairments. In 
specialized institution, little work linked to the school curriculum was observed. Therefore the conclusion may be that inclusion (regarding access only) has advanced at state schools, but not regarding quality of school processes.

KEYWORDS: Inclusive education. Teaching students with visual disabilities. Training of teachers for inclusive education.

\section{REFERÊNCIAS}

BRASIL. Ministério da Educação. Instituto Nacional de Estudos e Pesquisas Educacionais. Censo escolar da educação básica 2012: resumo técnico. Brasília: INEP, 2013. Disponível em:

<http://download.inep.gov.br/educacao_basica/censo_escolar/resumos_tecnicos/resumo _tecnico_censo_educacao_basica_2012.pdf>. Acesso em: 20 mai. 2013.

\section{Política Nacional de Educação Especial na Perspectiva da Educação}

Inclusiva. Brasília: MEC: SEESP, jan. 2008. Disponível em:

<portal.mec.gov.br/arquivos/pdf/politicaeducespecial.pdf>. Acesso em: 31 ago. 2008.

Ministério da Educação. Formação Continuada a Distância de Professores para o Atendimento Educacional Especializado Deficiência Visual. Brasília: Secretaria de Educação Especial, 2005.

Conselho Nacional de Educação. Conselho Pleno. Resolução CNE/CEB n.1, de 18 de fevereiro de 2002. Institui diretrizes para formação inicial de professores da educação básica, em nível superior, curso de licenciatura, de graduação plena. Diário Oficial da União, Brasília, DF, 18 fev. 2002. Disponível em: http://portal.mec.gov.br/cne/arquivos/pdf/rcp01_02.pdf Acesso em: 20 de maio de 2013.

. Ministério da Educação. Conselho Nacional de Educação. Parecer CNE/CEB n.17/2001, de 17 de agosto de 2001. Institui diretrizes nacionais para a Educação Especial na Educação Básica. Diário Oficial da União, Brasília, DF: Casa Civil, 2001a. Disponível em: <http://portal.mec.gov.br/seesp/arquivos/pdf/parecer17.pdf>. Acesso em: 20 mai. 2013.

. Ministério da Educação. Conselho Nacional de Educação. Resolução CNE/CEB n.2/2001, de 11 de set. 2001. Institui diretrizes nacionais para a Educação Especial na Educação Básica. Diário Oficial da União, Brasília, DF: Casa Civil, 2001b. Disponível em: <http://portal.mec.gov.br/cne/arquivos/pdf/CEB0201.pdf>. Acesso em: 20 mai. 2013.

Ministério da Educação. Conselho Nacional de Educação. Parecer CNE/CP n. 9/2001, de 18 de janeiro de 2002. Institui as Diretrizes Curriculares Nacionais para a Formação de Professores da Educação Básica, em nível superior, curso de licenciatura, de graduação plena. Diário Oficial da União, Brasília, DF: Casa Civil, 2001c. 
Disponível em: <http://portal.mec.gov.br/cne/arquivos/pdf/009.pdf〉. Acesso em: 20 mai. 2013.

DIAS, T. R. S.; OMOTE, S. Entrevista em Educação Especial: aspectos metodológicos. Revista Brasileira de Educação Especial, Marília, v.2, n.3, p. 93-100, 1995.

Disponível em: <http://educa.fcc.org.br/pdf/rbee/v02n03/v02n03a09.pdf>. Acesso em: 3 jun. 2014.

FARIAS, I. M. S. de (Org.). A organização do processo didático. In: (Org.). Didática e Docência: aprendendo a profissão. Brasília: Líber Livro, 2009. p.101-127.

HEREDERO, E. S. A escola inclusiva e estratégias para fazer frente a ela: as adaptações curriculares. Acta Scientiarum. Education, Maringá, v.32, n.2, p.193-208, 2010. Disponível em:

<http://eduem.uem.br/ojs/index.php/ActaSciEduc/article/download/9772/6417>. Acesso em: 3 jun. 2014.

JACCOUD, M.; MAYER, R. A observação direta e a pesquisa qualitativa. In: POUPART, J. et al. A Pesquisa Qualitativa: enfoques epistemológicos e metodológicos. Petrópolis, RJ: Vozes, 2008. p.254-294.

MENDES, E. G. A radicalização do debate sobre inclusão escolar no Brasil. Revista Brasileira de Educação, Rio de Janeiro, v.11, n.33, p.387-405, set./dez., 2006 .

PEDROSO, C. C. A.; CAMPOS, J. A. de P. P.; DUARTE, M. Formação de professores e educação inclusiva: análise das matrizes curriculares dos cursos de licenciatura. Educação Unisinos, São Leopoldo, RS, v.17, n.1, p.40-47, jan./abr. 2013. Disponível em: <http://revistas.unisinos.br/index.php/educacao/article/view/edu.2013.171.05/1411>. Acesso em: 29 abr. 2013.

PIETRO, R. G. Atendimento escolar de alunos com necessidades educacionais especiais; um olhar sobre as políticas públicas de educação no Brasil. In: MANTOAN, M. T. E.; PIETRO, R. G.; ARANTES, V. A. (Org.). Inclusão Escolar: pontos e contrapontos. São Paulo: Summus, 2006. p.31-73.

PIMENTA, S. G. De professores, pesquisa e didática. Campinas, SP: Papirus, 2002.

RODRIGUES, D. Dez ideias (mal) feitas sobre a educação inclusiva. In: (Org.). Inclusão e Educação: doze olhares sobre a educação inclusiva. São Paulo: Summus, 2006. p.299-318.

TRIVINOS, A. N. S. Introdução à pesquisa em ciências sociais: a pesquisa qualitativa em educação. São Paulo: Atlas, 2006. 